\title{
Hypothyroidism in Rheumatoid Arthritis - To Screen or Not to Screen?
}
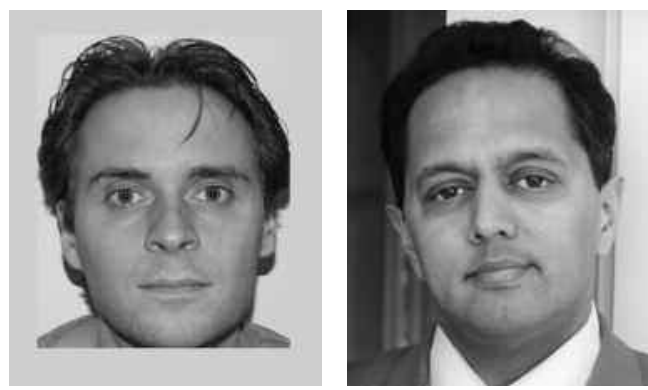

The manifestations of rheumatoid arthritis (RA) extend beyond the symmetrical inflammation of the joints, as shown by accumulating evidence of increased risk for comorbid conditions such as cardiovascular disease (CVD), the leading cause of death in patients with $\mathrm{RA}^{1,2}$. Osteoporosis, another well established comorbidity in RA and low bone mineral density, has been suggested to be associated with cardiovascular mortality as well ${ }^{3,4}$. These studies demonstrate the importance of alertness for comorbid conditions in RA since it is well known that in patients with chronic diseases coexisting comorbidity is often overlooked $^{5}$.

Interestingly, in this issue of The Journal, McCoy and colleagues report about another comorbidity in patients with RA that seems to be an important amplifier of cardiovascular risk: hypothyroidism ${ }^{6}$.

In the literature on associations between RA and hypothyroidism, which goes back to the $1960 \mathrm{~s}^{7,8}$, one of the first studies reported thyroiditis in up to $12 \%$ of patients with $\mathrm{RA}^{9}$. Major limitations of these studies were cross-sectional or observational designs and lack of "adequate" control groups.

To (partly) tackle these limitations and to elucidate whether hypothyroidism is more prevalent in patients with RA compared to non-RA subjects, McCoy and colleagues conducted a population-based cohort using data from the Rochester Epidemiology Project. In the study, 650 RA patients and 650 age- and sex-matched subjects without RA were identified to compare prevalences and incidences of hypothyroidism and CVD. Surprisingly, no statistically significant higher prevalence of hypothyroidism was observed in patients with RA compared to the non-RA subjects (16\% and $14 \%$, respectively; $\mathrm{p}=0.14$ ). These results are in contrast with other studies, such as the controlled investigation of Shiroky, et al in patients from a hospital clinic and a rheumatology practice ${ }^{10}$. In that study prevalences of hypothyroidism were assessed in $91 \mathrm{RA}$ patients and 93 control patients with noninflammatory rheumatic disease (i.e., fibromyalgia or osteoarthritis) and demographic fea- tures comparable to the patients with RA. The study revealed a 3-fold elevated prevalence (30\%) of thyroid disease in patients with RA compared to patients with noninflammatory rheumatic disease $(11 \%)^{10}$. Recently, we observed an approximately 2-fold higher prevalence of hypothyroidism in female patients with arthritis $(\mathrm{n}=1000$ : $6.5 \%)$ compared to controls ( $\mathrm{n}=173,500: 3.9 \%)$ ( $\mathrm{p}<$ 0.001 ) in a representative Dutch sample of 175,000 registered primary care patients ${ }^{11}$. Moreover, looking at the cumulative incidence of hypothyroid disease in the investigation of McCoy, et al, this also tends to be higher in patients with RA as compared to non-RA subjects (107 vs 88 events; $p=0.14$ ) and 10 -year incidence of $7.7 \%$ and $6.7 \%$, respectively. In addition, the cumulative incidence of hypothyroid disease might be underestimated in RA, since these patients had a shorter followup duration (7.9 years) compared to the non-RA subjects (9.0 years).

Finally, it is important to note that disease-modifying antirheumatic drugs and biological agents such as tumor necrosis factor blockers might improve thyroid function in clinically hypothyroid patients, and it was recently shown that adalimumab treatment improved thyroid function in hypothyroid patients with $\mathrm{RA}^{12}$.

Further, from an autoimmunity point of view, similar prevalences of hypothyroidism (which is predominately autoimmune-mediated) in RA and non-RA subjects were also not expected, since autoimmune diseases share similarities in genetic and immunological origin, as well as environmental risk factors, suggesting that autoimmune diseases have a tendency to cluster ${ }^{13,14}$. Explanations for the coexistence of autoimmune disorders involve immunological disturbances (in B and T lymphocytes), a trend to react abnormally in the presence of an antigen, and a genetic susceptibility ${ }^{15,16}$. Therefore, a higher coexistence of hypothyroidism is expected and was recently confirmed by the largest population-based study investigating this topic ${ }^{11}$.

As both hypothyroidism and RA are associated with an elevated CVD risk, McCoy, et al also examined the influence of thyroid disorders on development of CVD in CVD

\section{See Hypothyroidism as risk factor for CVD in RA, page 954}


event-naive patients with RA. They observed that hypothyroidism was significantly associated with CVD in patients with RA [hazard ratio (HR) 2; 95\% confidence interval (CI) $1.1,3.6]$, and this remained after adjustment for traditional cardiovascular risk factors (HR 2.0; 95\% CI 1.1, 3.6). These observations strengthen the described associations between hypothyroidism and an elevated risk of $\mathrm{CVD}^{17-20}$. Moreover, an even higher HR $(2.7 ; 95 \%$ CI 1.1-6.3) was observed in the subgroup of Hashimoto's thyroiditis, suggesting a possible autoimmune-mediated amplifying effect. In this respect, it is noteworthy that polymorphisms of protein tyrosine phosphate PTPN22, a susceptibility gene for a diverse spectrum of autoimmune diseases such as Hashimoto's thyroiditis and RA, accelerate atherosclerosis, suggesting autoimmunity itself may have a pathogenic role in CVD development ${ }^{21}$. This hypothesis is strengthened by the intriguing observation that L-thyroxine use was significantly associated with CVD in RA patients (HR 2.1; 95\% CI 1.2-3.8), indicating that L-thyroxine use may not decrease CVD development in hypothyroid RA patients, although further elaboration in prospective studies is needed.

Altogether, the occurrence of hypothyroidism in patients with RA has clinical relevance, since these patients are more prone to development of CVD, with approximately doubled CVD risk in comparison to the general population. As the increased (or actually amplified) CVD risk in hypothyroid patients with RA is independent of the traditional cardiovascular risk factors, clinicians need more awareness of hypothyroidism in RA, and a first step might be screening for thyroid disorders. In the coming decades we need to elucidate whether L-thyroxine substitution, in addition to (mandatory) CVD risk management according to international guidelines, lowers CVD development in hypothyroid patients with RA, as the investigation of McCoy and colleagues clearly underscores, increasing the evidence that hypothyroidism amplifies CVD risk in RA and is thus more than an innocent bystander.

\section{HENNIE G. RATERMAN, MD}

Department of Rheumatology,

VU University Medical Center;

MICHAEL T. NURMOHAMED, MD, PhD,

Department of Rheumatology,

Jan van Breemen Institute,

Jan van Breemenstraat 2,

Amsterdam, The Netherlands

Address correspondence to Dr. Nurmohamed.

E-mail:m.nurmohamed@reade.nl

\section{REFERENCES}

1. Peters MJ, van Halm VP, Voskuyl AE, Smulders YM, Boers M, Lems WF, et al. Does rheumatoid arthritis equal diabetes mellitus as an independent risk factor for cardiovascular disease? A prospective study. Arthritis Rheum 2009;61:1571-9.

2. Gabriel SE. Cardiovascular morbidity and mortality in rheumatoid arthritis. Am J Med 2008;121 Suppl 1:S9-14.
3. Haugeberg G, Uhlig T, Falch JA, Halse JI, Kvien TK. Bone mineral density and frequency of osteoporosis in female patients with rheumatoid arthritis: Results from 394 patients in the Oslo County Rheumatoid Arthritis Register. Arthritis Rheum 2000;43:522-30.

4. den Uyl D, Nurmohamed MT, van Tuyl LH, Raterman HG, Lems WF. (Sub)clinical cardiovascular disease is associated with increased bone loss and fracture risk; a systematic review of the association between cardiovascular disease and osteoporosis. Arthritis Res Ther 2011;13:R5.

5. Redelmeier DA, Tibshirani RJ. Driving fatalities on US presidential election days. JAMA 2008;300:1518-20.

6. McCoy S, Crowson CS, Gabriel SE, Matteson EL. Hypothyroidism as a risk factor for development of cardiovascular disease in patients with rheumatoid arthritis. J Rheumatol 2012;39:954-8.

7. Becker KL, Ferguson RH, McConahey WM. The connective-tissue diseases and symptoms associated with Hashimoto's thyroiditis. N Engl J Med 1963;268:277-80.

8. Hijmans W, Doniach D, Roitt IM, Holborow EJ. Serological overlap between lupus erythematosus, rheumatoid arthritis, and thyroid auto-immune disease. Br Med J 1961;2:909-14.

9. Hart FD. Rheumatoid arthritis: Extra-articular manifestations. II. Br Med J 1970;2:747-52.

10. Shiroky JB, Cohen M, Ballachey ML, Neville C. Thyroid dysfunction in rheumatoid arthritis: A controlled prospective survey. Ann Rheum Dis 1993;52:454-6.

11. Raterman HG, Nielen MM, Peters MJ, Verheij RA, Schellevis FG, Nurmohamed MT. Elevated prevalence hypothyroidism in female inflammatory arthritis patients in primary care amplifies the prevalence of cardiovascular disease [abstract]. Ann Rheum Dis 2011;70 Suppl 3:164

12. Raterman HG, Jamnitski A, Lems WF, Voskuyl AE, Dijkmans BA, Bos WH, et al. Improvement of thyroid function in hypothyroid patients with rheumatoid arthritis after 6 months of adalimumab treatment: A pilot study. J Rheumatol 2011;38:247-51.

13. Bach JF. The effect of infections on susceptibility to autoimmune and allergic diseases. N Engl J Med 2002;347:911-20.

14. Anaya JM, Corena R, Castiblanco J, Rojas-Villarraga A, Shoenfeld Y. The kaleidoscope of autoimmunity: Multiple autoimmune syndromes and familial autoimmunity. Exp Rev Clin Immunol 2007;3:623-35.

15. Eisenbarth GS, Gottlieb PA. Autoimmune polyendocrine syndromes. N Engl J Med 2004;350:2068-79.

16. Laivoranta-Nyman S, Mottonen T, Hermann R, Tuokko J, Luukkainen R, Hakala M, et al. HLA-DR-DQ haplotypes and genotypes in Finnish patients with rheumatoid arthritis. Ann Rheum Dis 2004;63:1406-12.

17. Raterman HG, van Halm VP, Voskuyl AE, Simsek S, Dijkmans BAC, Nurmohamed MT. Rheumatoid arthritis is associated with a high prevalence of hypothyroidism that amplifies its cardiovascular risk. Ann Rheum Dis 2008;67:229-32.

18. Raterman HG, van Eijk I, Voskuyl AE, Peters MJ, Dijkmans BA, van Halm VP, et al. The metabolic syndrome is amplified in hypothyroid rheumatoid arthritis patients: A cross-sectional study. Ann Rheum Dis 2010;69:39-42.

19. Dessein PH, Norton GR, Woodiwiss AJ, Joffe BI, Wolfe F. Influence of nonclassical cardiovascular risk factors on the accuracy of predicting subclinical atherosclerosis in rheumatoid arthritis. J Rheumatol 2007;34:943-51.

20. Schott LL, Kao AH, Cunningham A, Wildman RP, Kuller LH, Sutton-Tyrrell K, et al. Do carotid artery diameters manifest early evidence of atherosclerosis in women with rheumatoid arthritis? J Womens Health 2009;18:21-9.

21. Pertovaara M, Raitala A, Juonala M, Kahonen M, Lehtimaki T, Viikari JS, et al. Autoimmunity and atherosclerosis: Functional polymorphism of PTPN22 is associated with phenotypes related to the risk of atherosclerosis. The Cardiovascular Risk in Young Finns Study. Clin Exp Immunol 2007;147:265-9.

J Rheumatol 2012;39:885-6; doi:10.3899/jrheum.120015 